\title{
Chronic Exposure to Altered Gravity During the Pregnancy-to-Lactation Transition Affects Abundance of Cytoskeletal Proteins in the Rat Mammary Gland
}

\author{
Kibrom M. Alula ${ }^{1}$, James H. Resau ${ }^{2}$, and Osman V. Patel ${ }^{1}$ \\ ${ }^{1}$ Department of Cell and Molecular Biology, Grand Valley State University, Allendale, MI; ${ }^{2}$ BioSpecimen Science, \\ Van Andel Institute, Grand Rapids, MI
}

\begin{abstract}
The mammogenic, lactogenic, and lactopoetic effects of prolactin (PRL) in the mammary gland are mediated through a specific cytokine receptor, the PRL-receptor (PRLR). PRLR is anchored to the cytoskeleton and its activation, and subsequent signal transduction, is dependent on an integral/intact cytoskeletal organization. Previous studies revealed a down-regulation of PRLR and reduced metabolic output in the mammary gland of rats exposed to hypergravity (HG). Therefore, the objective of this study was to use quantitative immunohistochemistry to determine the effects of HG exposure during pregnancy on the pre- and postpartum abundance of the cytoskeletal proteins in the rat mammary gland. Pregnant rats were exposed to either $2 \mathrm{xg}$ [HG] or $1 \mathrm{xg}$ [Stationary control (SC)] from days 11 to 20 of gestation
\end{abstract}

Key words: $\quad$ Rat; Mammary Gland; Gravity; Cytoskeleton; Lactation; Pregnancy; Immunohistochemistry

Correspondence to: Osman V. Patel

Department of Cell and Molecular Biology

Grand Valley State University

3300a Kindschi Hall of Science

1 Campus Drive

Allendale, MI 49401

Telephone: 616-331-8930

E-mail: patelo@gvsu.edu
(G20) through postpartum days 1 (P1) and 3 (P3). Spectral characterization and quantitation of each antigen (actin, tubulin, cytokeratin, and vimentin) per lobule (n=3-7 lobules/micrograph; 4 micrographs/slide) was computed using the CRi Nuance multispectral system. At G20 and P3, increased $(p<0.001)$ amounts of actin, tubulin, cytokeratin, and vimentin were detected in HG rats. Tubulin, cytokeratin, and vimentin were overexpressed $(\mathrm{p}<0.01)$ in HG group compared to SC at P1. These results suggest that atypical composition of cytoskeletal proteins contribute to the aberrant lactogenic signal transduction and associated reduced postpartum mammary metabolic output in rats exposed to altered inertial environment.

$\begin{array}{ll}\text { ABBREVIATIONS } \\ \text { G9 } & \text { Gestation day 9 } \\ \text { G20 } & \text { Gestation day 20 } \\ \text { HG } & \text { Hypergravity } \\ \text { IHC } & \text { Immunohistochemistry } \\ \text { P1 } & \text { Postpartum day 1 } \\ \text { P3 } & \text { Postpartum day 3 } \\ \text { PRL } & \text { Prolactin } \\ \text { PRLR } & \text { Prolactin Receptor } \\ \text { Px } & \text { Pixel } \\ \text { SC } & \text { Stationary Control } \\ \text { SEM } & \text { Standard Error of the Mean }\end{array}$




\section{INTRODUCTION}

The mammary gland undergoes significant structural and functional transformation during the physiological phases of pregnancy, lactation, and involution. These changes are evident in both the secretory (epithelial) and non-secretory (stromal) support structures of the organ. The epithelial alveolar and myo-epithelial cells facilitate synthesis and delivery of milk (Richert et al., 2000), while the non-secretory assemblage of the extracellular matrix provides key structural and metabolic support to the gland. The dynamic rearrangement of the extracellular matrix throughout the distinct developmental stages is vital to the biochemical and biophysical morphogenesis of the organ (Masso-Welch et al., 2000). Importantly, critical changes in the mammary gland's parenchymal architecture, cytoskeletal remodeling, and acquisition of biosynthetic competence occur mainly during the postnatal period, primarily during pregnancy.

Hormonal signals are indispensable for orchestrating mammary gland development during mammogenesis, lactogenesis, and galactopoiesis. During pregnancy, the dramatic growth and functional differentiation of the gland is dependent on prolactin (PRL) secreted by the pituitary gland (Ormandy et al., 1997; Topper and Freeman, 1980). In addition, the role of PRL in alveologenesis, milk synthesis, and galactopoiesis in various species is well documented (Brisken et al., 1999; Hennighausen and Robinson, 2005). PRL also regulates the synthesis and transport of the complex mixture of nutrients dispersed in milk (Bole-Feysot et al., 1998; Ormandy et al., 1997). The distinct effects of PRL in the mammary gland are mediated principally by membrane-anchored receptors (Bole-Feysot et al., 1998). Notably, an intact cytoskeleton is critical for the transmembrane activation and transduction of these pleiotropic PRL signals through the prolactin receptor (PRLR) (Zoubiane et al., 2004).

The cytoskeleton is an interconnected lattice of microfilaments, intermediate filaments, and microtubules that extends throughout the cytoplasm. Its dynamic and adaptive configuration is vital for cell architecture, organelle movement, cytokinesis, and extracellular environment sensing (Flusberg et al., 2001; Hughes-Fulford, 2003). The cytoskeleton plays a key role in coordinating the communication between the extra- and intracellular signals in tandem with mediating cell-to-cell interactions (Janmey, 1998). Actin and tubulin are crucial for the PRL-dependent development of the mammary gland (Zoubiane et al., 2004). Aberrations in the cytoskeletal structure are known to disrupt intracellular signaling machinery and impact functional output (Flusberg et al., 2001; Hughes-Fulford, 2003). Therefore, precise cytoskeletal composition and assembly are instrumental in the global development of the mammary gland, architectural alignment of the mammary tissue elements, and synchronization of functionality through coordinated extra- and intracellular interactions (Xu et al., 2009).

Spaceflight and other gravitational load ( $g$ load) studies have shown the diverse effects of altered gravity on reproduction and mammary gland function (Bojados and Jamon, 2011; Casey et al., 2015; Casey et al., 2012; Lintault et al., 2007; Megory and Oyama, 1984; Plaut et al., 1999; Simeoni et al., 2005). Interestingly, results from microgravity and hypergravity (HG) studies show a continuum of responses for a number of biological systems, including the mammary gland (Casey et al., 2015; Plaut et al., 2003). Although HG exposure had no effect on the number of pups born, $50 \%$ of the pups from HG dams do not survive beyond 48 h (Casey et al., 2012; Lintault et al., 2007). Furthermore, lipogenesis in the mammary gland is impaired in altered gravity (Casey et al., 2012; Lintault et al., 2007; Patel et al., 2008). Results from an earlier study suggest that HG-exposed mammary gland metabolic output may be mediated by factors other than PRL and glucocorticoid (Patel et al., 2008). Plausibly, exposure to HG alters the mammary gland microenvironment, which adversely impacts physiological output and potentially compromises pups' survival.

The cytoskeleton is responsible for sensing changes in $g$-load and mediating structural remodeling and related signal transduction (Dai et al., 2006). Studies utilizing normal and cancerous human cells (Carlsson et al., 2003; Carmeliet et al., 1998; Rosner et al., 2006; Sciola et al., 1999), as well as plants (Braun et al., 2002; Himmelspach et al., 1999), have shown that exposure to diverse $g$-loads leads to an alteration in cytoskeletal organization and distribution. 
Specifically, atypical levels of microfilaments, microtubules, and intermediate filaments have been associated with abnormal karyokinesis and cytokenesis (Carlsson et al., 2003; Carmeliet et al., 1998; Meloni et al., 2006; Rosner et al., 2006; Sciola et al., 1999). Although the above studies provide an understanding of the multiple effects of altered gravity on the mechanical support structures of a cell, there is no report on the effect of altered gravity on these proteins in a dynamic organ like the mammary gland across different physiological states.

Despite the description of the effects of HG on pregnancy and lactation (Casey et al., 2012; Lintault et al., 2007; Megory and Oyama, 1984; Plaut et al., 1999; Simeoni et al., 2005), the mechanism(s) eliciting these aberrations are not completely understood. Moreover, the integrity of cytoskeletal structure is crucial for PRL-mediated pre- and postpartum mammary gland development (Zoubiane et al., 2004), but the impact of HG on the cytoskeletal proteins is not clearly understood. Therefore, we hypothesize that reduced lipogenesis in the HG-exposed mammary gland is induced by anomalies in the cytoskeletal architecture. In this study, we intended to quantify the effect of HG on the cytoskeletal protein abundance during the pregnancy-to-lactation transition in the rat mammary gland.

\section{METHODS}

\section{Animals and Treatment Conditions}

The use of female Sprague-Dawley rats (Taconic Farms, Germantown, NY) and associated research protocols were reviewed and approved by NASA's Ames Research Center Institutional Animal Care and Use Committee as reported earlier (Lintault et al., 2007; Patel et al., 2008; Plaut et al., 2003). On gestation day 9 (G9) animals were randomly assigned to either the control group or one of three experimental conditions. These experimental conditions were pregnant (G20, $n=4-6)$, postpartum (lactation) day 1 (P1, $\mathrm{n}=4-6)$, and postpartum day $3(\mathrm{P} 3, \mathrm{n}=4-6)$. During the period of observation, the dams were individually housed in maternity cages and maintained under standard colony conditions (12:12 light/dark cycle [0600:1800]; $21 \pm 1^{\circ} \mathrm{C}$ at 30 - 50\% humidity). The HG dams were placed on NASA Ames Research Center's $24 \mathrm{ft}$ centrifuge on day G9 and allowed to acclimatize to continuous 2xg force for $48 \mathrm{~h}$ (Lintault et al., 2007; Patel et al., 2008; Plaut et al., 2003). During the acclimation phase, animal behavior, feeding, body temperature, and weights were observed and monitored. The stationary control (SC) dams that were exposed to $1 \mathrm{xg}$ were housed in the same room as the HG rats and placed in identical cages to ensure that all groups were exposed to the same environmental conditions (light, sound, temperature, and humidity). The HG (G20, P1, and P3) experimental animals and their respective stationary controls were humanely sacrificed using isoflurane gas. Abdominal mammary gland tissue was then collected as described previously (Patel et al., 2008). The animals from SC and HG groups were sacrificed at the same time in the circadian cycle. During the experimental period, the centrifuge was paused on a daily basis for about an hour to clean cages and replenish food and water, as well as to monitor animal behavior and overall health.

\section{Immunohistochemistry}

The tissue for immunohistochemistry was initially fixed in $10 \%$ neutral-buffered formalin, and later embedded in paraffin. Thereafter, the preparation of tissue sections (5 $\mu \mathrm{m}$ thickness) and the immunohistochemistry staining protocol were similar to that described elsewhere (Bruxvoort et al., 2007; Cao et al., 2013). Staining for each antibody was optimized using Ventana's automated staining system (Discovery XT, Ventana Medical Systems, Tucson, AZ) and each slide was simultaneously stained with two primary antibodies. The primary antibodies utilized were rabbit monoclonal anti-alpha-smooth muscle actin (RB 9010-P0, Neomarkers, Fremont, CA) and mouse monoclonal anti-alpha-tubulin (DM1A, Sigma, St. Louis, MO) on one slide. The other slide was stained with rabbit anti-cytokeratin (180052, Life Technologies, Grand Island, NY) and mouse monoclonal anti-vimentin (18-0052, Invitrogen, Camarillo, CA) antibodies. Reactions were observed on the above double-antibody stained slides by incubating with anti-mouse/antirabbit multimers [Horseradish peroxidase (Diaminobenzidine), Alkaline phosphatase (Liquid permanent red)] (Ventana Medical Systems, Tucson, AZ). Hematoxylin was utilized as a nuclear-specific counterstain. 


\section{Imaging and Multi-Spectral Analysis}

Digital micrographs were obtained (10X and 40X magnifications) from each of the G20, P1, and P3 slides using a Brightfield microscope (Nikon Eclipse 80i, Nikon Corporation, Japan). Thereafter, quantitative immunohistochemistry (IHC) analysis was done using the CRi Nuance Multispectral Imaging System (Caliper Life Sciences, MA) as detailed by others (Fiore et al., 2012; Huang et al., 2013). Initially, a spectral library was created for each chromogen as described elsewhere (Fiore et al., 2012; Huang et al., 2013), and then randomly selected lobules ( $\mathrm{n}=3-7$ lobules/micrograph; 4 micrographs/slide) were traced using the free-pen tool and analyzed using the automated macros of the Nuance software. Next, the integrated algorithm of the software was used to quantify the staining density per antigen [pixel (px) count] within the traced lobule. The abundance of each immunostain per lobule was then normalized to the hematoxylin counterstain. The Nuance software allowed us to unmix each chromogen and quantify them separately as shown in Figure 1.

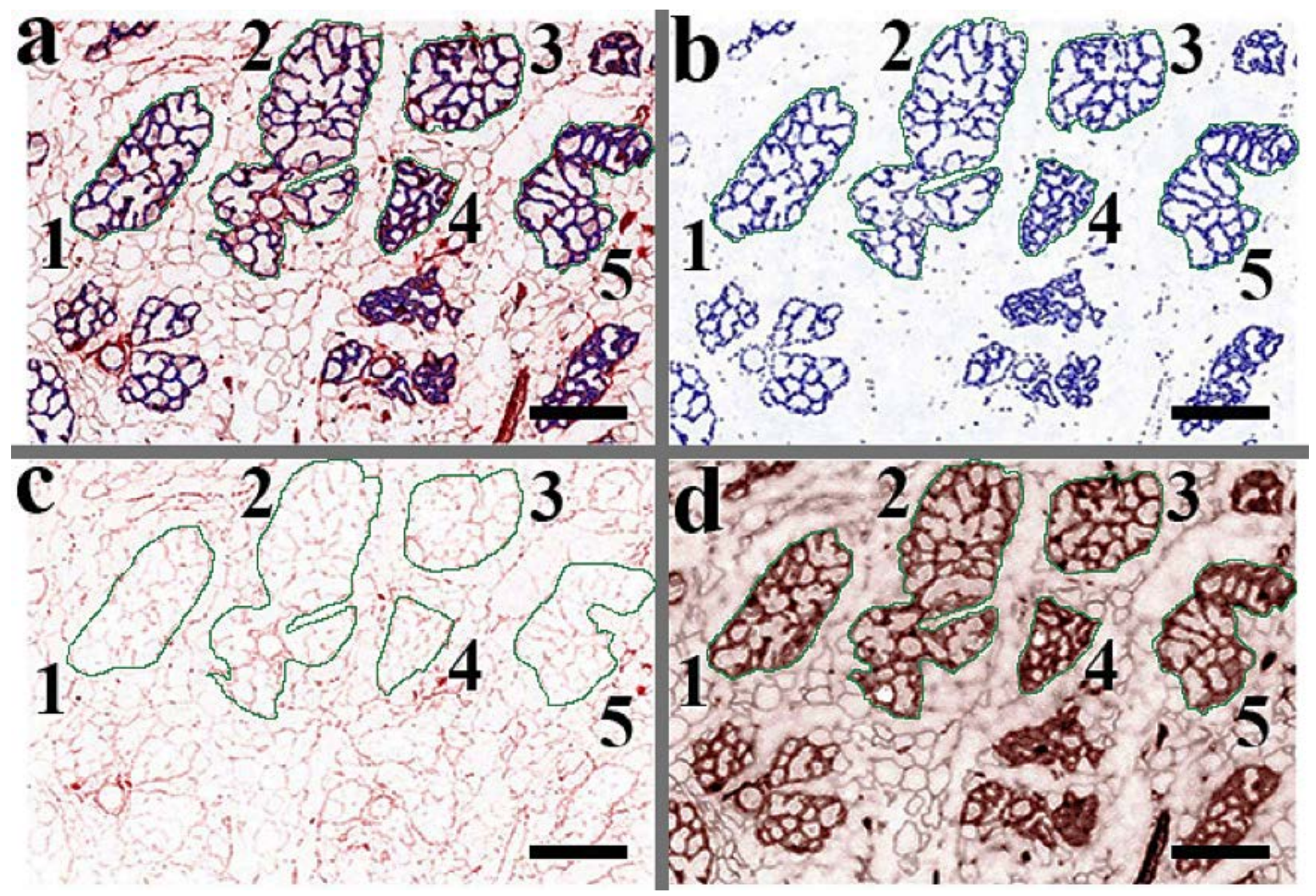

Figure 1. Representative images of lobular outlining and unmixing for protein quantification. (a) An overlay image. (b) Overlay image unmixed into blue hematoxylin. (c) Overlay image unmixed into red cytokeratin. (d) Overlay image unmixed into brown vimentin. The unmixed images of a multi-labeled slide enable quantification of individual, as well as overlapping signals within the same outlined lobular border. The scale bar represents $50 \mathrm{\mu m}(10 \mathrm{X}$ magnification) in the photomicrographs.

\section{Statistical Analysis}

Data within a group [G20 vs P1, G20 vs P3, and P1 vs P3 for HG and SC, respectively) and between groups [HG vs SC within G20, P1, and
P3, respectively] were analyzed using Student's ttest (Graph Pad Prism Software 6.07, San Diego, CA). Data are expressed as mean \pm SEM and $\mathrm{p}<0.05$ was considered as significant. 


\section{RESULTS}

We utilized IHC followed by image analysis using the spectral-spatial features of the CRi Nuance Multispectral Imaging System to investigate the effect of altered gravity on the abundance of cytoskeletal and intermediate filament proteins in pregnant Sprague-Dawley rats.

First, we determined the unique spectral characteristics of each dye/chromophore utilizing the Nuance software and then applied these same spectral parameters to every imaged section for quantification. As illustrated in Figure 1, the ability of the program to distinctly separate counterstain (hematoxylin) from the target analytes allowed us to calculate and express per lobule the amount of each chromophore per unit of DNA staining. We were also able to determine the pixel (px) counts [x,y coordinates] of the paired antigens to find out which ones co-localize and co-express the chromophores.

\section{Expression Levels of Microfilament and Microtubular Proteins}

Figure 2 shows multiplexed IHC chromogenic intensity of actin (red) and tubulin (brown) proteins at 10X (Figure 2a), and 40X (Figure 2b) magnifications at G20, P1, and P3 within our targeted region of interest (lobules) in the mammary glands of HG and SC animals. The micrographs demonstrate that the microfilament and microtubular proteins are expressed during pregnancy and lactation in both groups of animals.

Figure 3 provides a quantitative comparison of mammary gland lobular actin and tubulin proteins measured in stationary-control (SC) and hypergravity-exposed (HG) rat groups. Specifically, Figure 3a shows that the actin abundance was lowest at G20 $(0.8 \pm 0.05 \mathrm{px})$ and then increased $(p<0.001)$ by about two-fold $(1.8 \pm 0.11 \mathrm{px})$ at $\mathrm{P} 1$ in SC animals. Thereafter, the actin levels further increased $(\mathrm{p}<0.01)$ by about $40 \%(2.4 \pm 0.11 \mathrm{px})$ by P3 in relation to P1 levels in SC group. On the other hand, there was no difference between G20 (2.1 $\pm 0.1 \mathrm{px})$ and P1 $(2.08 \pm 0.1 \mathrm{px})$ actin amounts in the HG group (Figure 3a). The actin $(2.9 \pm 0.17 \mathrm{px})$ levels then increased by approximately $40 \%(\mathrm{p}<0.001)$ by P3 compared to P1 stage in HG rats. On the other hand, stage-specific comparison across treatment groups (SC vs HG) reveals that the HG animals express over two-fold $(\mathrm{p}<0.001)$ more actin protein at G20 and approximately 30\% higher $(\mathrm{p}<0.01)$ levels at P3 compared to the corresponding SC cohorts (Figure 3b).

There was no difference in the expression of tubulin between G20 $(12.0 \pm 0.83 \mathrm{px}), \quad \mathrm{P} 1$ (11.8 $\pm 0.77 \mathrm{px})$, and P3 $(13.4 \pm 0.92 \mathrm{px})$ in the SC rats (Figure 3c). In contrast, the HG group displayed a disparate temporal profile such that the highest $(p<0.0001)$ amount of tubulin immunostain was present at P3 $(23.4 \pm 1.41 \mathrm{px})$ and the lowest at $\mathrm{P} 1(9.4 \pm 0.40 \mathrm{px})$ (Figure $3 \mathrm{c}$ ). Furthermore, the HG animals expressed about $50 \%$ to $75 \%$ more tubulin protein at G20 $(\mathrm{p}<0.001)$ and P3 $(\mathrm{p}<0.001)$, respectively, in comparison to the same time-points in SC group (Figure 3d).

\section{Expression Levels of Intermediate-Filament Proteins}

The subcellular distribution of cytokeratin (red) and vimentin (brown) using multiplexed IHC is depicted in Figure 4. Following image acquisition, the nuclear and cytoplasmic analytes were unmixed, and each protein was separately quantitated based on the spectral libraries created using Nuance Imaging System. Figure 5 provides a quantitative comparison of mammary gland lobular cytokeratin and vimentin proteins measured in stationary-control (SC) and hypergravity-exposed (HG) rat groups A threefold $(p<0.0001)$ increase in the expression of cytokeratin was noted from G20 $(0.084 \pm 0.008 \mathrm{px})$ to $\mathrm{P} 1(0.27 \pm 0.008 \mathrm{px})$ in the SC animals, followed by a further increase by about $50 \%(\mathrm{p}<0.05)$ by P3 $(0.38 \pm 0.04 \mathrm{px})$ relative to $\mathrm{P} 1$ amounts (Figure $5 \mathrm{a}$ ). A similar trend of time course increase in the expression of cytokeratin from pregnancy to lactation was detected in the HG group (Figure $5 a)$. However, the HG rats expressed about $75 \%$ $(\mathrm{p}<0.0001)$ more cytokeratin at G20 $(0.084 \pm 0.008$ vs $0.14 \pm 0.008 \mathrm{px}$ ), as well as approximately $60 \%$ $(\mathrm{p}<0.005)$ more at $\mathrm{P} 1(0.27 \pm 0.008$ vs $0.44 \pm 0.05$ $\mathrm{px})$ and P3 $(0.61 \pm 0.05$ vs $0.38 \pm 0.04 \mathrm{px})$, respective to their SC cohorts (Figure $5 b$ ).

There was a stage-specific surge in vimentin quantity in SC rats, such that it increased by about three-fold $(\mathrm{p}<0.0001)$ between G20 and P1 

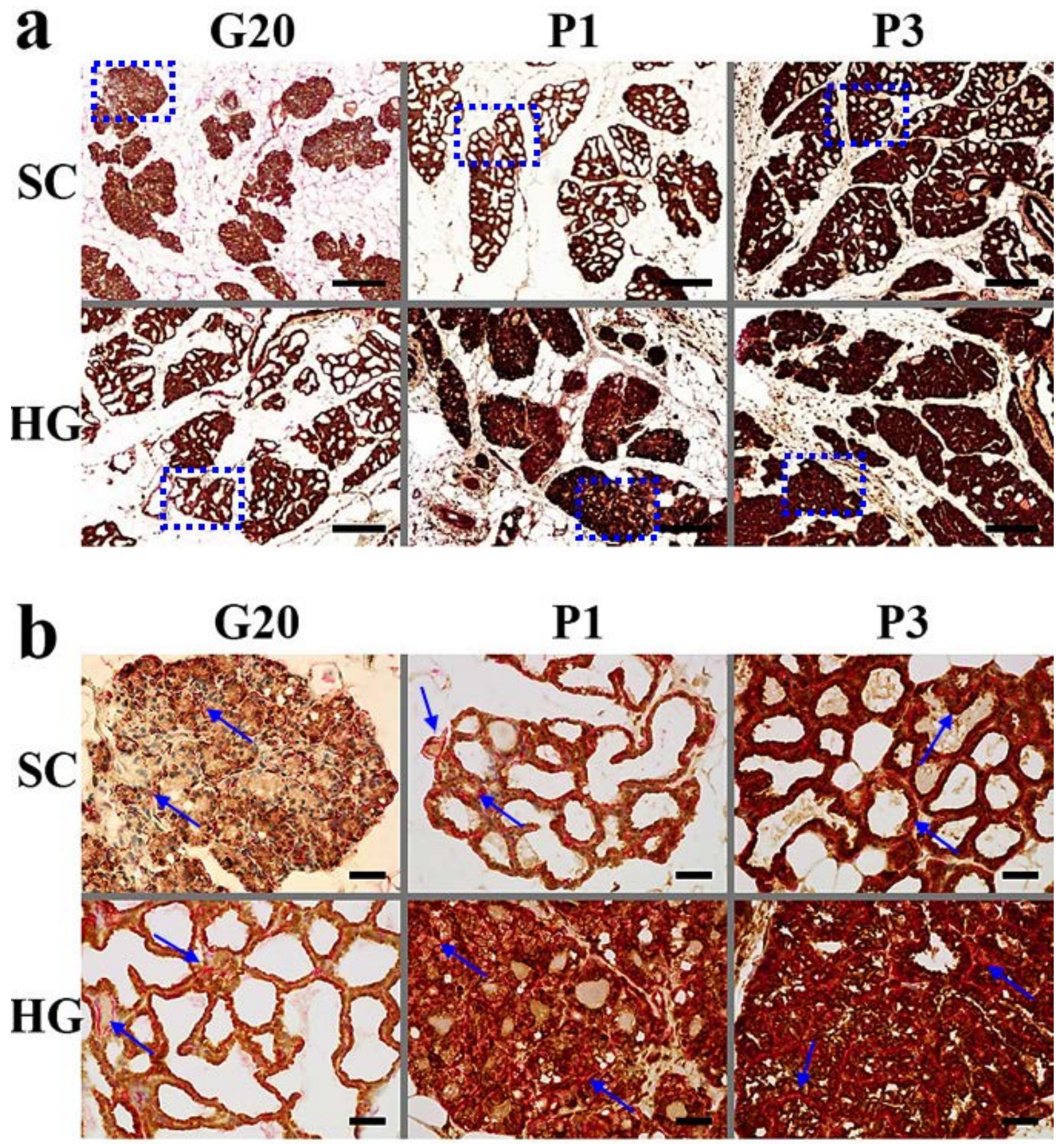

Figure 2. Representative immunohistochemistry (IHC) sections of rat mammary gland from stationarycontrol (SC) and hypergravity-exposed (HG) animals at day 20 of gestation (G20), postpartum day 1 (P1), and postpartum day 3 (P3), stained for actin (red) and tubulin (brown). (a) Photomicrographs at 10X magnification with scale bar representing $50 \mu \mathrm{m}$. Boxes represent images at 40X. (b) Photomicrographs at 40X magnifications with scale bar representing $25 \mu \mathrm{m}$ and arrows point to actin stained in red.

( $0.99 \pm 0.03$ vs $2.9 \pm 0.06 \mathrm{px})$, as well as between $\mathrm{P} 1$ and P3 (2.9 \pm 0.06 vs $8.1 \pm 0.32 \mathrm{px})$ (Figure $5 \mathrm{c}$ ). In contrast, vimentin levels increased by about $50 \%$ $(\mathrm{p}<0.0001)$ between $\mathrm{G} 20$ and $\mathrm{P} 1 \quad(2.9 \pm 0.08$ vs $4.5 \pm 0.28 \mathrm{px})$, followed by a $300 \%(\mathrm{p}<0.0001)$ increase between P1 and P3 (4.5 \pm 0.28 vs $13.5 \pm 1.3$ 
px) in the HG group (Figure 5c). Moreover, the HG animals expressed about three-fold $(\mathrm{p}<0.0001)$ more vimentin protein at G20 $(0.99 \pm 0.03$ vs $2.9 \pm 0.08 \mathrm{px})$ compared to SC rats (Figure 5d). Similarly, the amount of vimentin protein at P1 ( $4.5 \pm 0.28$ vs $2.9 \pm 0.06 \mathrm{px})$ and P3 $(13.5 \pm 1.3$ vs $8.1 \pm 0.32 \mathrm{px})$ was higher by about $50 \%(\mathrm{p}<0.0001)$ in HG animals compared to the same stage in SC group (Figure 5d).
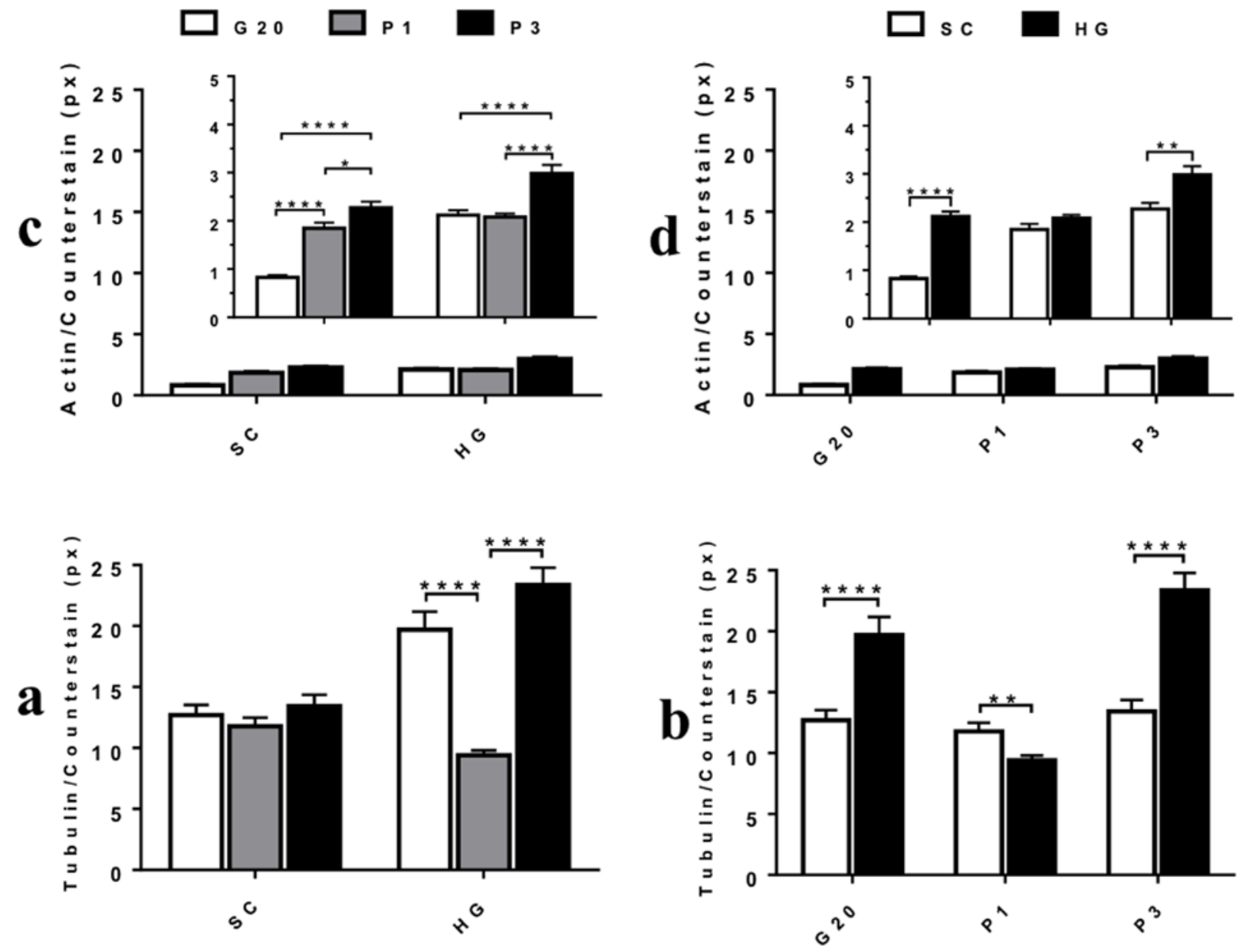

Figure 3. Quantitative comparison of mammary gland lobular actin and tubulin proteins measured in stationary-control (SC) and hypergravity-exposed (HG) rat groups following unmixing of chromophores using the CRi Nuance Multispectral Imaging System at day 20 of gestation (G20), postpartum day 1 (P1), and postpartum day 3 (P3). (a) Comparison of actin levels within groups. (b) Comparison of actin levels between groups. (c) Comparison of tubulin levels within groups. (d) Comparison of tubulin levels between groups. Data are shown as Mean \pm SEM; ${ }^{*}$ means within and between each group are significantly different $\left({ }^{*} \mathbf{p}<0.01\right.$; $\left.{ }^{* *} \mathbf{p}<0.005 ; * * * * \mathbf{p}<0.0001\right)$. The scale has been expanded in insert Figure $3 a$ and $3 b$ to display the relationship of the quantified actin protein. 
Alula et al. -- Mammary Gland Cytoskeletal Composition in Altered Gravity

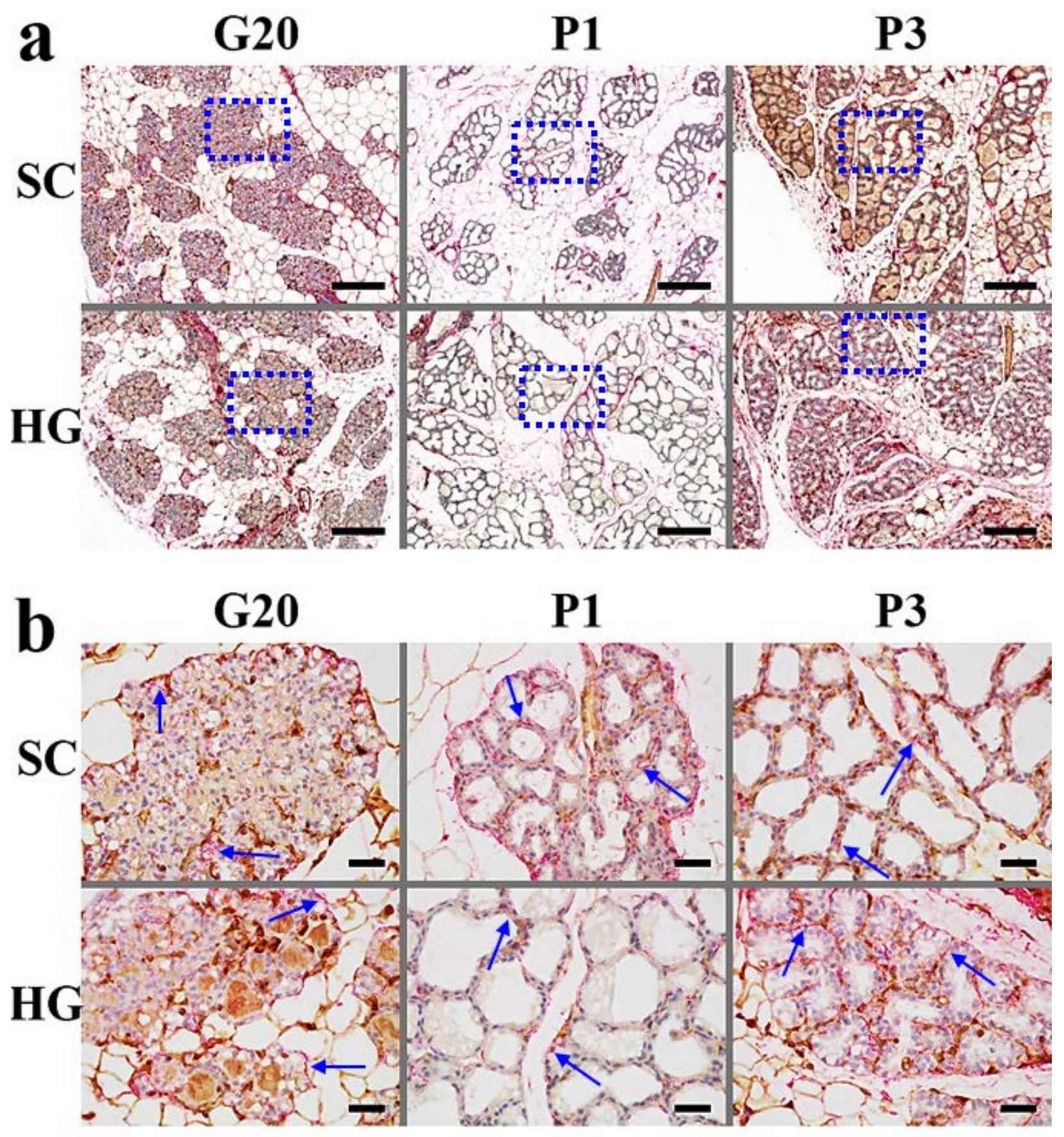

Figure 4. Representative immunohistochemistry (IHC) sections of rat mammary gland from stationarycontrol (SC) and hypergravity-exposed (HG) animals at day 20 of gestation (G20), postpartum day 1 (P1), and postpartum day 3 (P3), stained for cytokeratin (red) and vimentin (brown). (a) Photomicrographs at 10X magnification with scale bar representing $50 \mu \mathrm{m}$. Boxes represent images at 40X. (b) Photomicrographs at 40X magnifications with scale bar representing $25 \mu \mathrm{m}$ and arrows point to cytokeratin stained in red. 

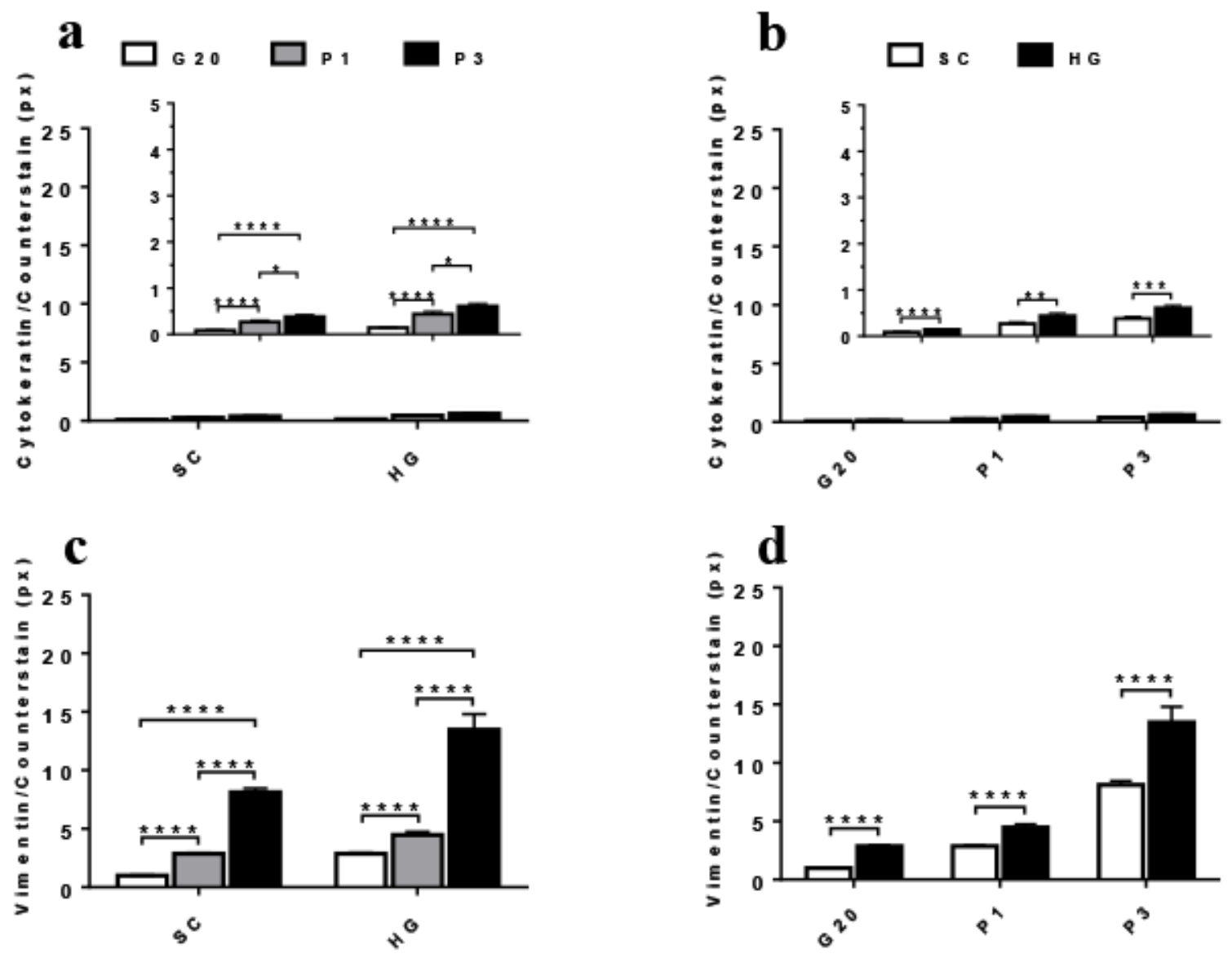

Figure 5. Quantitative comparison of mammary gland lobular cytokeratin and vimentin proteins measured in stationary-control (SC) and hypergravity-exposed (HG) rat groups following unmixing of chromophores using the CRi Nuance Multispectral Imaging System at day 20 of gestation (G20), postpartum day 1 (P1), and postpartum day 3 (P3). (a) Comparison of cytokeratin levels within groups. (b) Comparison of cytokeratin levels between groups. (c) Comparison of vimentin levels within groups. (d) Comparison of vimentin levels between groups. Data are shown as Mean \pm SEM; ${ }^{*}$ means within and between each group are significantly different $(* \mathbf{p}<0.05 ; * * p<0.005$; $* * * \mathbf{p}<0.001 ; * * * * \mathbf{p}<0.0001)$. The scale has been expanded in insert Figure $5 a$ and $5 b$ to display the relationship of the quantified cytokeratin protein.

\section{DISCUSSION}

We investigated the spatiotemporal distribution of the cytoskeleton in the mammary gland during mammogenesis and lactogenesis, during a period of altered gravity using a rat model. To our knowledge, the allotment of cytoskeletal elements in the mammary gland during the pregnancy to lactation transition has not been characterized. In addition, the impact of altered inertial force on the distribution of these cytoskeletal components across the physiological phases of pregnancy and lactation has also not been described. We observed that an adjustment of $g$-load distorts the abundance of microfilaments during physiological phases of both pregnancy and lactation (Figure 3). Our findings, however, show that the abundance of actin proteins during pregnancy and lactation was increased $(\mathrm{p}<0.001)$ in the mammary gland of HG rats. We noted that the effect of HG on the expression of actin was more pronounced during the transition between 
mammogenesis and lactogenesis. A similar change in actin levels was reported from cancer cells exposed to short term parabolic flight maneuvers (Corydon et al., 2016) and random positioning machine or clinostat exposure (Svejgaard et al., 2015), as well as endothelial cells exposed to HG (Cazzaniga et al., 2014) or microgravity (Janmaleki et al., 2016). Many other studies have reported the immediate effects of gravitation fields on microfilament organization using an array of cells and tissues (Streuli, 1999; Himmelspach et al., 1999; Papaseit et al., 2000; Uva et al., 2002; Hughes-Fulford, 2003; Corydon et al., 2016). In concert with these reports, our results confirm that exposure to chronic HG not only alters the spatiotemporal pattern of expression of the microfilaments, but also markedly increases the quantity of microfilaments across two critically important physiological phases of pregnancy and lactation. However, additional studies are necessary to verify whether the observed changes are due to aberrant synthesis, inhibition of degradation, or redistribution.

We found that the abundance of tubulin protein during pregnancy and early lactation (day 3) was significantly increased in the mammary gland of HG rats, with the difference being higher during lactation compared to pregnancy. Tubulin content does increase in the mammary gland with the morphogenesis of lubolo-alveolar units during pregnancy and milk secretory activation (Brisken et al., 1999; Brisken and O'Malley, 2010; Janmey, 1998; Loizzi and Shao, 1990). The upsurge in tubulin supports the increased synthetic activity of mammary epithelial cells and the intracellular transport of secretory vesicles for exocytosis (Loizzi and Shao, 1990). Therefore, the increased levels of tubulin levels at G20 and P3 in HG animals do suggest that an alteration in $g$-load induces a dysregulation of tubulin expression at these key phases of mammary gland differentiation. In human neuroblastoma cells, changes in gravitational acceleration modified the modular and spatial arrangements of microtubules, including their orientation (Rosner et al., 2006), polymerization (Portet et al., 2003), and nuclear structural morphology (CrawfordYoung, 2006). In rats, a 10\% increase in tubulin polymerization occurs during pregnancy, with a further graduated increase to peak by about three- fold at lactation (Loizzi and Shao, 1990). This dynamic adjustment in tubulin content coupled with polymerization during lactation are pivotal for optimum galactopoiesis (Janmey, 1998; Loizzi and Shao, 1990). However, in this study, we did not explicitly assess the impact of HG on tubulin polymerization and protofilament formation in the mammary gland across the studied physiological stages.

Cytokeratins are intermediate filaments found in cells of epithelial origin and are involved in various functions ranging from cellular tensegrity to protein localization to mechano-transduction (Grimm et al., 2006). In addition, these intermediate filaments are the most resilient of the intracytoplasmic filaments and they form a basket-like structure to anchor the nucleus to the cytoplasm. It is known that modification of gravitational acceleration distorts this meshwork of cytokeratin (Vassy et al., 2001), as well as leads to an aberrant expression of cytokeratin genes in endothelial cells (Grosse et al., 2012). Likewise, other studies reported disorganization and rearrangement of intermediate filaments in cancer cells (Ulbrich et al., 2011), endothelial cells (Wehland et al., 2013), and chondrocytes (Aleshcheva et al., 2015). Lactational incompetence, milk content alteration, and atypical lobulo-alveolar patterning is reported with reduction in cytokeratin (Grimm et al., 2006; Hadsell et al., 2007; Sun et al., 2010). However, the specific impact of increased levels of cytokeratin on mammary gland morphology and associated functional output requires elucidation. Overall, our results using the rat mammary gland model are consistent with these earlier studies demonstrating that adjustments in gravity do influence intracellular intermediate filament accretion.

Vimentin is also an intermediate filament that is found in cells of mesenchymal origin. It is part of the intracellular scaffolding that plays an important role in organelle organization, cell attachment, and signaling (Eckes et al., 1998; Satelli and Li, 2011). Like keratins, vimentin is affected by gravitational fields (Eckes et al., 1998; Ulbrich et al., 2011; Ma et al., 2013; Aleshcheva et al., 2015; Maier et al., 2015). On the other hand, overexpression of vimentin has been reported in a wide array of cancers and has been linked to facilitating metastases of tumors (Satelli 
and $\mathrm{Li}, 2011$ ). Our findings are in agreement with earlier studies (Ma et al., 2013; Maier et al., 2015; Ulbrich et al., 2011) and show that the intermediate filament vimentin is significantly elevated in HG-exposed rats during all key stages of mammary gland development. However, additional studies are needed to determine the precise influence of this increased accretion of vimentin on optimum mammary gland physiology.

Our earlier studies (Casey et al., 2015; Patel et al., 2008) have shown that exposure to altered gravity did not affect gestational length, litter size, or duration of labor or parturition. However, pup survival dropped from $95 \%$ at day of parturition to approximately $50 \%$ by P3 in HG group (Casey et al., 2012). While milk bands were visible in the HG pups, it was noted that HG dams spent significantly more time nursing compared to their counterparts (Casey et al., 2012; Patel et al., 2008). Interestingly, actin-deficient mice also display precocious lactation and prolonged nursing (Haaksma et al., 2011; Weymouth et al., 2012). However, actin-null mice failed to nurture their offspring effectively (Haaksma et al., 2011; Weymouth et al., 2012). Similar to the HG pups, pups from actin-null mice fail to gain weight and over $60 \%$ postnatal mortality was reported (Haaksma et al., 2011; Weymouth et al., 2012). Cross-fostering of both HG and actin-null mice from the day of parturition to their respective nonmanipulated controls increased pup survival in both groups to about 90\% (Casey et al., 2012; Haaksma et al., 2011; Weymouth et al., 2012). This suggests that the stunted growth noted in HG and actin-deficient pups was not due to an anomaly in the pups but associated with impaired lactation triggered by the disruption of cytoskeleton in the dam's mammary gland.

Previous studies established that body and mammary gland weights, along with fat stores, were significantly reduced in rats exposed to altered gravity (Casey et al., 2012; Patel et al., 2008). Notably, a similar phenotype has been previously described in PRLR-knockout mice (Freemark et al., 2001). Our earlier study revealed aberrant levels of PRLR, together with atypical spatiotemporal expression pattern in a number of metabolically important organs of animals exposed to altered gravity (Casey et al., 2012; Patel et al., 2008). Moreover, it is established that an integral cytoskeletal microenvironment is necessary to orchestrate the PRL-driven mammary cell differentiation and metabolic homeostasis via the cognate receptor, PRLR (Oakes et al., 2006; Zoubiane et al., 2004). Therefore, the atypical spatiotemporal profile of PRLR observed in our earlier studies (Casey et al., 2012; Patel et al., 2008), is plausibly triggered by the aberrant cytoskeleton architecture observed in the present study. Similarly, the inability to reverse the lactational defect observed in HGexposed dams through supplementation with lactogenic hormones (Patel et al., 2008) might be partially explained by the failure of the impaired cytoskeleton found in this investigation to constitutively transduce the downstream lactogenic signal.

\section{CONCLUSION}

Previous studies attributed the reduced postpartum mammary metabolic output and increased pup mortality rates to deviant PRL secretion and abnormal PRLR expression. The current study reveals that the atypical cytoskeletal architecture may be triggering the reduced postpartum mammary metabolic output in rats exposed to altered gravity. We hypothesize that the impaired cytoskeleton significantly modifies the microenvironment and leads to asynchronous lactogenic signaling by altering the expression of PRLR in the mammary gland.

\section{ACKNOWLEDGEMENTS}

A particular debt of gratitude is owed to Dr. Karen Plaut (Purdue University) and her collaborators for sharing tissue collected through their NASA grant NNA05CP91A. Appreciation is also extended to Bree Berghuis, Kristen Feenstra, and Eric Hudson of Van Andel Institute for their expert help with immunohistochemistry and image analysis.

\section{REFERENCES}

Aleshcheva G, Wehland M, Sahana J, Bauer J, Corydon TJ, Hemmersbach R, Frett T, Egli M, Infanger M, Grosse J, Grimm D (2015) Moderate alterations of the cytoskeleton in human chondrocytes after short-term microgravity produced by parabolic flight maneuvers could be prevented by up- 
regulation of BMP-2 and SOX-9. FASEB Journal 29: 2303-2314

Bojados M, Jamon M (2011) Exposure to hypergravity during specific developmental periods differentially affects metabolism and vestibular reactions in adult C57BL /6j mice. European Journal of Neuroscience 34: 2024-2034

Bole-Feysot C, Goffin V, Edery M, Binart N, Kelly PA (1998) Prolactin (PRL) and its receptor: actions, signal transduction pathways and phenotypes observed in PRL receptor knockout mice. Endocrine Reviews 19: $225-268$

Braun M, Buchen B, Sievers A (2002) Actomyosin-mediated statolith positioning in gravisensing plant cells studied in microgravity. Journal of Plant Growth Regulation 21: 137-145

Brisken C, Kaur S, Chavarria TE, Binart N, Sutherland RL, Weinberg RA, Kelly PA, Ormandy CJ (1999) Prolactin controls mammary gland development via direct and indirect mechanisms. Developmental Biology 210: 96-106

Brisken C, O'Malley B (2010) Hormone action in the mammary gland. Cold Spring Harbor Perspectives in Biology 2: a003178

Bruxvoort KJ, Charbonneau HM, Giambernardi TA, Goolsby JC, Qian CN, Zylstra CR, Robinson DR, Roy-Burman P, Shaw AK, Buckner-Berghuis BD, Sigler RE, Resau JH, Sullivan R, Bushman W, Williams BO (2007) Inactivation of Apc in the mouse prostate causes prostate carcinoma. Cancer Research 67: 2490-2496

Cao Y, Zhang ZL, Zhou M, Elson P, Rini B, Aydin H, Feenstra K, Tan MH, Berghuis B, Tabbey R, Resau JH, Zhou FJ, Teh BT, Qian CN (2013) Pericyte coverage of differentiated vessels inside tumor vasculature is an independent unfavorable prognostic factor for patients with clear cell renal cell carcinoma. Cancer 119: 313-324

Carlsson SIM, Bertilaccio MTS, Ballabio E, Maier JAM (2003) Endothelial stress by gravitational unloading: effects on cell growth and cytoskeletal organization. Biochemica et Biophysica Acta 1642: 173179
Carmeliet G, Nys G, Stockmans I, Bouillon R (1998) Gene expression related to the differentiation of osteoblastic cells is altered by microgravity. Bone 22: 139s-143s

Casey T, Patel OV, Plaut K (2015) Transcriptomes reveal alterations in gravity impact circadian clocks and activate mechanotransduction pathways with adaptation through epigenetic change. Physiological Genomics 47: 113-128

Casey T, Zakrzewska EI, Maple RL, Lintault L, Wade CE, Baer LA, Ronca AE, Plaut K (2012) Hypergravity disruption of homeorhetic adaptations to lactation in rat dams include changes in circadian clocks. Biology Open 1: 570-581

Cazzaniga A, Castiglioni S, Maier JAM (2014) Conditioned media from microvascular endothelial cells cultured in simulated microgravity inhibit osteoblast activity. Biomed Research International 2014: Article ID 857934

Corydon TJ, Kopp S, Wehland M, Braun M, Schutte A, Mayer T, Hulsing T, Oltmann H, Schmitz B, Hemmersbach R, Grimm D (2016) Alterations of the cytoskeleton in human cells in space proved by life-cell imaging. Scientific Reports 6: 20043

Crawford-Young SJ (2006) Effects of microgravity on cell cytoskeleton and embryogenesis. International Journal of Developmental Biology 50: 183-191

Dai ZQ, Li YH, Ding B, Zhang XY, Tan YJ, Wan YM (2006) Actin microfilaments participate in the regulation of the COL1A1 promoter activity in ROS17/2.8 cells under simulated microgravity. Advances in Space Research 38: $1159-1167$

Eckes B, Dogic D, Colucci-Guyon E, Wang N, Maniotis A, Ingber D, Merckling A, Langa F, Aumailley M, Delouvee A, Koteliansky V, Babinet C, Krieg T (1998) Impaired mechanical stability, migration and contractile capacity in vimentin-deficient fibroblasts. Journal of Cell Science 111: 1897-1907

Fiore C, Bailey D, Conlon N, Wu X, Martin N, Fiorentino M, Finn S, Fall K, Andersson SO, Andren O, Loda M, Flavin R (2012) Utility of multispectral imaging in 
automated quantitative scoring of immunohistochemistry. Journal of Clinical Pathology 65: 496-502

Flusberg DA, Numaguchi Y, Ingber DE (2001) Cooperative control of Akt phosphorylation, bcl-2 expression, and apoptosis by cytoskeletal microfilaments and microtubules in capillary endothelial cells. Molecular Biology of the Cell 12: 30873094

Freemark M, Fleenor D, Driscoll P, Binart N, Kelly PA (2001) Body weight and fat deposition in prolactin receptor-deficient mice. Endocrinology 142: 532-537

Grimm SL, Bu W, Longley MA, Roop DR, Li Y, Rosen JM (2006) Keratin 6 is not essential for mammary gland development. Breast Cancer Research 8: R29

Grosse J, Wehland M, Pietsch J, Ma X, Ulbrich C, Schulz H, Saar K, Hubner N, Hauslage J, Hemmersbach R, Braun M, van Loon J, Vagt $N$, Infanger $M$, Eilles $C$, Egli $M$, Richter P, Baltz T, Einspanier R, Sharbati S, Grimm D (2012) Short-term weightlessness produced by parabolic flight maneuvers altered gene expression patterns in human endothelial cells. FASEB Journal 26: 639655

Haaksma CJ, Schwartz RJ, Tomasek JJ (2011) Myoepithelial cell contraction and milk ejection are impaired in mammary glands of mice lacking smooth muscle alpha-actin. Biology of Reproduction 85: 13-21

Hadsell DL, Olea W, Lawrence N, George J, Torres D, Kadowaki T, Lee AV (2007) Decreased lactation capacity and altered milk composition in insulin receptor substrate null mice is associated with decreased maternal body mass and reduced insulin-dependent phosphorylation of mammary Akt. Journal of Endocrinology 194: $327-336$

Hennighausen L, Robinson GW (2005) Information networks in the mammary gland. Nature Reviews Molecular Cell Biology 6: 715-725

Himmelspach R, Wymer CL, Lloyd CW, Nick P (1999) Gravity-induced reorientation of cortical microtubules observed in vivo. Plant Journal 18: 449-453
Huang W, Hennrick K, Drew S (2013) A colorful future of quantitative pathology: validation of Vectra technology using chromogenic multiplexed immunohistochemistry and prostate tissue microarrays. Human Pathology 44: 29-38

Hughes-Fulford M (2003) Function of the cytoskeleton in gravisensing during spaceflight. Advances in Space Research 32: 1585-1593

Janmaleki M, Pachenari M, Seyedpour SM, Shahghadami R, Sanati-Nezhad A (2016) Impact of simulated microgravity on cytoskeleton and viscoelastic properties of endothelial cell. Scientific Reports 6: 32418

Janmey PA (1998) The cytoskeleton and cell signaling: component localization and mechanical coupling. Physiological Reviews 78: $763-781$

Lintault LM, Zakrzewska EI, Maple RL, Baer LA, Casey TM, Ronca AE, Wade CE, Plaut K (2007) In a hypergravity environment neonatal survival is adversely affected by alterations in dam tissue metabolism rather than reduced food intake. Journal of Applied Physiology 102: 2186-2193

Loizzi RF, Shao D (1990) Tubulin increases with lactation in rat and guinea-pig mammary alveolar cells - fluorescence and em immunogold localization. Protoplasma 159: 129-143

Ma X, Wehland M, Aleshcheva G, Hauslage J, Wasser $\mathrm{K}$, Hemmersbach $\mathrm{R}$, Infanger $\mathrm{M}$, Bauer J, Grimm D (2013) Interleukin-6 expression under gravitational stress due to vibration and hypergravity in follicular thyroid cancer cells. PLOS One 8: e68140

Maier JA, Cialdai F, Monici M, Morbidelli L (2015) The impact of microgravity and hypergravity on endothelial cells. Biomed Research International 2015: 434803

Masso-Welch PA, Darcy KM, Stangle-Castor NC, Ip MM (2000) A developmental atlas of rat mammary gland histology. Journal of Mammary Gland Biology and Neoplasia 5: 165-185

Megory E, Oyama J (1984) Hypergravity effects on litter size, nursing activity, prolactin, TSH, T3, and T4 in the rat. Aviation, Space, and Environmental Medicine 55: 1129-1135 
Meloni MA, Galleri G, Pippia P, Cogoli-Greuter $M$ (2006) Cytoskeleton changes and impaired motility of monocytes at modelled low gravity. Protoplasma 229: 243-249

Oakes SR, Hilton HN, Ormandy CJ (2006) The alveolar switch: coordinating the proliferative cues and cell fate decisions that drive the formation of lobuloalveoli from ductal epithelium. Breast Cancer Research 8: 207

Ormandy CJ, Camus A, Barra J, Damotte D, Lucas B, Buteau H, Edery M, Brousse N, Babinet C, Binart N, Kelly PA (1997) Null mutation of the prolactin receptor gene produces multiple reproductive defects in the mouse. Genes \& Development 11: 167178

Papaseit C, Pochon N, Tabony J (2000) Microtubule self-organization is gravitydependent. Proceedings of the National Academy of Sciences USA 97: 8364-8368

Patel OV, Zakrzewska E, Maple RL, Baer LA, Ronca AE, Wade CE, Plaut K (2008) Lipogenesis impaired in periparturient rats exposed to altered gravity is independent of prolactin and glucocorticoid secretion. European Journal of Applied Physiology 104: 847-858

Plaut K, Maple R, Vyas C, Munaim S, Darling A, Casey T, Alberts JR (1999) The effects of spaceflight on mammary metabolism in pregnant rats. Proceedings of the Society of Experimental Biology and Medicine 222: 85-89

Plaut K, Maple RL, Wade CE, Baer LA, Ronca AE (2003) Effects of hypergravity on mammary metabolic function: gravity acts as a continuum. Journal of Applied Physiology 95: 2350-2354

Portet S, Tuszynski JA, Dixon JM, Sataric MV (2003) Models of spatial and orientational self-organization of microtubules under the influence of gravitational fields. Physical Review E 68: 021903

Richert MM, Schwertfeger KL, Ryder JW, Anderson SM (2000) An atlas of mouse mammary gland development. Journal of Mammary Gland Biology and Neoplasia 5: 227-241

Rosner H, Wassermann T, Moller W, Hanke W (2006) Effects of altered gravity on the actin and microtubule cytoskeleton of human SHSY5Y neuroblastoma cells. Protoplasma 229: $225-234$

Satelli A, Li SL (2011) Vimentin in cancer and its potential as a molecular target for cancer therapy. Cellular and Molecular Life Sciences 68: 3033-3046

Sciola L, Cogoli-Greuter M, Cogoli A, Spano A, Pippia P (1999) Influence of microgravity on mitogen finding and cytoskeleton in Jurkat cells. Advances in Space Research 24: 801-805

Simeoni M, Francia N, Santucci D, Chiarotti F, Alleva E (2005) Effects of acute hypergravity exposure and parity on maternal behavior in CD-1 mice. Acta Neurobiologiae Experimentalis 65: 151-160

Streuli C (1999) Extracellular matrix remodelling and cellular differentiation. Current Opinion in Cell Biology 11: 634-640

Sun P, Yuan Y, Li A, Li B, Dai X (2010) Cytokeratin expression during mouse embryonic and early postnatal mammary gland development. Histochemistry and Cell Biology 133: 213-221

Svejgaard B, Wehland M, Ma X, Kopp S, Sahana J, Warnke E, Aleshcheva G, Hemmersbach R, Hauslage J, Grosse J, Bauer J, Corydon TJ, Islam T, Infanger M, Grimm D (2015) Common effects on cancer cells exerted by a random positioning machine and a $2 \mathrm{~d}$ clinostat. PLOS One 10: e0135157

Topper YJ, Freeman CS (1980) Multiple hormone interactions in the developmental biology of the mammary gland. Physiological Reviews 60: $1049-1106$

Ulbrich C, Pietsch J, Grosse J, Wehland M, Schulz H, Saar K, Hubner N, Hauslage J, Hemmersbach R, Braun M, van Loon J, Vagt N, Egli M, Richter P, Einspanier R, Sharbati S, Baltz T, Infanger M, Ma X, Grimm D (2011) Differential gene regulation under altered gravity conditions in follicular thyroid cancer cells: relationship between the extracellular matrix and the cytoskeleton. Cellular Physiology and Biochemistry 28: 185-198

Uva BM, Masini MA, Sturla M, Prato P, Passalacqua M, Giuliani M, Tagliafierro G, Strollo F (2002) Clinorotation-induced weightlessness influences the cytoskeleton 
of glial cells in culture. Brain Research 934: 132-139

Vassy J, Portet S, Beil M, Millot G, FauvelLafeve F, Karniguian A, Gasset G, Irinopoulou T, Calvo F, Rigaut JP, Schoevaert D (2001) The effect of weightlessness on cytoskeleton architecture and proliferation of human breast cancer cell line MCF-7. FASEB Journal 15: 11041106

Wehland M, Ma X, Braun M, Hauslage J, Hemmersbach R, Bauer J, Grosse J, Infanger M, Grimm D (2013) The impact of altered gravity and vibration on endothelial cells during a parabolic flight. Cellular Physiology and Biochemistry 31: 432-451
Weymouth N, Shi ZD, Rockey DC (2012) Smooth muscle alpha actin is specifically required for the maintenance of lactation. Developmental Biology 363: 1-14

Xu R, Boudreau A, Bissell MJ (2009) Tissue architecture and function: dynamic reciprocity via extra- and intra-cellular matrices. Cancer Metastasis Reviews 28: 167-176

Zoubiane GS, Valentijn A, Lowe ET, Akhtar N, Bagley S, Gilmore AP, Streuli CH (2004) A role for the cytoskeleton in prolactindependent mammary epithelial cell differentiation. Journal of Cell Science 117: 271-280 